\title{
What Factors Affect Teachers Using iPads in their Classrooms?
}

\author{
Phu Vu \\ University of Nebraska at Kearney
}

Author Note

Some data reported in this article comes from the author's doctoral dissertation (Vu, 2013)

\begin{abstract}
This study used a qualitative paradigm to discover what types of training teachers have received that resulted in successful use of iPads and what factors affect their decisions to use iPads in their classrooms. Data for this study were 21 interviews with 21 in-service teachers. The findings showed that the majority of teachers did not have any formal iPad training. All reported they had to resort to different sources such as self-learning and colleagues' support to learn about how to integrate iPads and useful apps into their teaching. There are many factors affecting their use of iPads in their classrooms. The study concluded with discussions and implications for school administrators and teachers.
\end{abstract}

Keywords: iPad; technology integration; in-service teacher training

In its latest report, the Center for American Progress (2013) argued

Far too often, school leaders fail to consider how technology might dramatically improve teaching and learning, and schools frequently acquire digital devices without discrete learning goals and ultimately use these devices in ways that fail to adequately serve students, schools, or taxpayers. (Center for American Progress, 2013, para. 2)

According to the report, the reasons for ineffective technology integration in American public school systems included the following: schools' resistance to change, lack of a performance-based environment, lack of incentives and support necessary to try new things, little flexibility to spend educational funds and teachers' technology competencies. This report echoed findings from a previous study concerning public school teachers' use of iPads in their teaching (Vu, Mclntyre \& Cepero (2014). The study found that teachers in public schools used iPads from one or two times a month up to several times during an entire semester, while private school teachers used iPads on a weekly basis. It was noteworthy that all participating teachers' schools considered them to be technologically well informed. These findings, along with the report by the Center for American Progress prompted the question of what factors made teachers in one school, but not in others, use iPads so often in their classrooms. 


\section{Literature Review}

\section{Teachers' Perceptions and Attitudes toward Technology Integration in their Classroom}

Studies have been widely conducted about in-service teachers' perceptions and attitudes toward technology integration in their classroom. In a survey with 225 practicing teachers or certified education professionals, Banas (2010) reported that $52 \%$ of participants had positive attitudes toward technology and were integrating technology in their instruction. Twenty-eight percent of the participants had positive feelings, but cited obstacles with integration, $13 \%$ were fully integrating technology and $7 \%$ were not integrating any technology. Banas' findings were in line with the Bill \& Melinda Gates Foundation's 2012 report "Technology and Effective Teaching." According to this report, based on a survey of 400 teachers from across the U.S., a large majority of classroom teachers use computer-related technology in their classrooms, but are still wary. The report revealed that $67 \%$ of teachers use technology in every class and $85 \%$ use it daily. Also, according to the report, the teachers' goal was to help their students learn -they remained skeptical, however, as there was little widely accepted proof that technology tools provided real value for student learning. In the same year, a national survey from PBS Learning Media found that $93 \%$ of K-12 teachers believed that technology such as interactive whiteboards enriched classroom education. Eighty-one percent felt the same way about tablets. The literature indicates a trend toward an increased positive perception of, and attitude towards, technology integration in education. This study goes further by examining whether these positive perceptions and attitudes translate into increased use of iPads by teachers in their classrooms.

\section{Using iPads in classrooms}

Several studies reported a positive impact on teaching and learning performance from iPad use in K-12 classrooms. In his study, Walter (2011) reported many advantages of iPads including: allowing a smooth transition from software-specific projects with a steep learning curve to smaller scale apps-based learning tasks, ease of use with apps instead of software training, as well as portability and kinesthetic interactions that traditional desktop or laptop computers could not offer. In another study by Vu, Mclntyre and Cepero (2014) examining how teachers used iPads in the classroom, the authors found that the students mostly used iPads for their class activities at the "knowledge representation" level of Bloom's Taxonomy. According to the teachers in the study, the use of the iPad in their classroom was somewhat useful (2.75 out of 5.00). One of the few early reports about the success of iPad implementation programs is about the use of iPads as a vehicle for intervention strategies with a fifth grade struggling reader with Attention Deficit Hyperactivity Disorder. McClanahan, Williams, Kennedy and Tate (2012) reported that comparisons of pre- and post-assessments showed the student had achieved one year's growth in reading within a six week time period. The student also gained in confidence and sense of being in control of his learning. 
The positive impact of the use of iPads in the classroom was also reported outside the United States. Speirs (2011) reported a successful implementation of iPads at his school in Greenock, Scotland. One hundred and fifteen iPads were deployed, one to each student and staff member. The children could keep the tablet all day, and those aged 10 and older could bring them home at night. The school's IT staff did not tell the teachers what the iPads were for, but made them always available for instructor use. According to Speirs, the biggest early change was in teaching art. Apps such as Brushes, MoodBoard Pro, and Photoshop Express allowed students to experiment and build confidence. Usually, children were reluctant to try new things in art class for fear of getting something incorrect. With unlimited undo functionality and the freedom simply to try things, their imagination opened up dramatically. Similarly in the English classroom, teachers now had to teach the art of keeping to a word limit, because their students were producing longer and better pieces of writing than ever before.

\section{Factors that affect effective use of technology in classrooms}

There are many factors related to the successful integration of technology into classrooms. Some of the most important factors include: finding sufficient annual funding, establishing dynamic plans, and decisions made concerning platforms, hardware, and software. According to many researchers (Bitner \& Bitner, 2002; Hew \& Brush; 2007; Ringstaff \& Kelly, 2002; Zhao, Pugh, \& Sheldon, 2002), while these factors are probably the most obvious considerations, an often-overlooked but decisive factor of whether technology succeeds or fails in the classroom is the teachers themselves. Although attention in selecting suitable hardware and software for classroom use is essential, it is the skills, competences and attitudes of the teachers that determine the effectiveness of technology integration into the curriculum. Bitner and Bitner (2002) summarized the factors required to see effective technology integration by teachers in schools:

a. Overcoming fear of change: Implementing new technology as a teaching and learning tool in the classroom results in fear and anxiety because it requires changes in classroom procedures and practices as well as the use of oftenunfamiliar technologies.

b. Training in basics: Teachers must have a fundamental understanding of how to operate a specific technology provided to them. It is also imperative they know how to perform basic tasks such as program installation, backing up files and deletion.

c. Personal use: Personal technology competencies are a way to cultivate the teacher's interest. Those who use personal digital programs such as word processors, spreadsheets, PowerPoint presentations and graphics programs - to name a few - on a regular basis, tend to be more comfortable with learning how new technology can make their teaching jobs easier and more effective.

d. Teaching models: Teachers need to be aware of how the use of various programs enhances their teaching and students' learning outcomes. Achievement occurs if teachers actually see technology demonstrations and attend training workshops. It 
is imperative that teachers have the knowledge to utilize different kinds of programs for both large and small group instruction.

e. Learning based: Learning should be the impetus that drives the use of technology in schools. Technology integration can enable teachers and learners to become partners in the learning process. Technology can also help replace the traditional paradigm of the teacher offering - and learners absorbing-knowledge with a new paradigm, in which both the teacher and learners collaborate with each other to achieve new knowledge.

f. Climate: The creation of a supportive climate, or constructive learning atmosphere, allows teachers to experiment without fear of failure.

g. Motivation: Motivation to overcome the frustration and confusion of the change process needs to be present. Intrinsic motivation will come if teachers see the benefits that new technology can provide their learners.

h. Support: Technical support for teachers, both ongoing and onsite, is imperative. Teachers need prompt support to be effective in integrating technology in their teaching.

\section{Methodology}

This study used a qualitative paradigm to answer the following research questions:

1. What types of training experiences have teachers had to use iPads in their classrooms?

2. What factors affect teachers using iPads in their classrooms?

According to Merriam (1998), the strength of qualitative research is its ability to offer complex textual descriptions of how people experience a given research issue. It also provides information about the "human" side of an issue. This study used a convenience sample of 21 elementary and secondary teachers in the southern Illinois area who had been using iPads in their classrooms. Through personal and professional contacts, a list of 35 elementary and middle school teachers who had been using iPads in their teaching for at least a semester was compiled. The same 35 teachers received emails, inviting them to participate in the study. A follow-up email was sent within two weeks as a reminder. Additionally, some of the teachers were contacted by telephone and others were contacted in person, either by the leading researcher or by a colleague, to increase the rate of participation. Twenty-three teachers agreed to participate in this study. Interview schedules were arranged with the teachers. Two teachers withdrew from the study due to personal reasons. The final number of participants was 21 . 
An interview protocol was used to collect data and was developed prior to the interviews; the questions guided conversation. The question order and information addressed were specified in advance; the sequence and wording were defined. Minimization of researcher bias was achieved through careful, detailed, thorough documentation of all interviews. Ten face-to-face interviews were recorded with a digital recorder while 11 online interviews were conducted through Gmail chat or Skype using "SuperTintin Call Recorder" software. In order to avoid any mismatching, all interviews were coded and then transcribed. Detailed written notes were not taken during the audiotaped interviews. The recorded interviews were transcribed verbatim. According to Merriam (1998), verbatim transcriptions of recorded interviews provide the best data for analysis.

In addition, upon completing the analysis of all 21 interview transcripts, five written transcripts were randomly selected to analyze and send to the participants, asking for signed verification of content accuracy for the interviews transcribed. These participants were also asked to rewrite, clarify, or make notes on either the transcripts or analyses if further clarifications were needed. This strategy is known as member checking, a validity strategy used to establish the accuracy of findings by taking the final report or themes back to the participants to determine whether the participants themselves feel the information is accurate (Creswell, 2003).

Finally, to minimize bias and to strengthen the interpreted findings written in the interview analyses, a colleague considered an expert in qualitative research methods crosschecked the researchers' analytical skills. The crosscheck resulted in the writing of two interview analyses, which were then compared with the original results. To facilitate this trial analysis process, two interview transcripts were run in NVivo 10, a qualitative data analysis program. An attempt was made to use this software to code and conduct the entire data analysis. However, the software was unable to code and analyze the data as expected, resulting in the use of the "Most Frequency Words" component in the transcripts.

After identifying the "Most Frequency Words" in the 21 transcripts, the coding and theme analysis process was performed manually. Data analysis did not always proceed in a linear manner, but was an ongoing search for general statements about relationships between categories of data. The transcripts were analyzed through the coding process, including open coding, axial coding, and selective coding. Themes that emerged from the coding also were compared to data observations to determine patterns.

\section{Findings}

\section{Research Question 1. What Types of Training Have the Teachers Experienced to Use iPads in the Classrooms?}

To gain the information for this research question, the participants were asked three subquestions in the interviews. 
1. What types of iPad training did you receive before using it in your teaching?

2. What do you think about the training? Is it sufficient and helpful?

3. Did you take any informal learning through your colleagues or by yourself, etc. to learn how to use it?

From the responses to the first question, several types of iPad training received by the participants before using iPads in their classrooms were identified. The most common training type was self-training. Thirteen of 21 participating teachers reported that they did not receive any formal iPad training before using iPads in their classrooms. According to seven teachers in the same public school, they did not receive any formal training in iPad use, besides a formal training session provided by an Apple sales representative. They resorted to different sources to educate themselves about how to use iPads in the classroom. Lindsey said that her husband was an engineer and was technologically perceptive, so he showed her how to use an iPad and "awesome apps" related to her subject area he found on the App Store. Six other private school teachers reported that they did not have any training, program or workshop before using iPad.s They all attended a "tech camp" in the summer to learn how to integrate a variety of technology into their classrooms. This "tech camp" came before the introduction of iPads to their school, and did not cover the use of iPads. According to these teachers, the "tech camp" was not considered formal iPad training. They managed to learn how to use iPads by searching for information on the Internet or by asking colleagues for help. Another type of training was through attending an iPad-integrated course provided by a professor at a Midwestern university. Eight teachers from different school districts attended this course and were introduced how to integrate iPads into their subject area teaching.

The second question focused on the effectiveness of the training. Six private school teachers, who did not attend any iPad training workshop, skipped this question. Seven public school teachers in the same school district attended a training workshop presented by an Apple sales representative. They indicated that the training was not really useful because the sales representative only introduced them to basic features of the iPad, such as how to turn it off and on, how to charge it, how to use the web browser, how to search and download apps from the Apple app store...etc. According to Kim, a teacher who attended that training session, she did not learn anything new. She had already used her iPad at home for two years, so she already knew how to use an iPad. Sharing the same idea, Keith said,

I expected more from him [Apple sales representative] to introduce us to useful educational apps or kind of experience, but it turned out a kind of product introduction. The information probably was useful for those who did not use the iPad before.

In contrast with the preceding experiences, those teachers who took an iPad-integrated course at the university held that the training was practical because it introduced them to useful apps to implement in their lessons. Nick noted that he appreciated that the 
professor introduced him to many interesting free apps he could integrate into his science class. Similarly, Rose said that the course was an eye opening experience for her to learn about virtual simulations, animations and apps in science teaching in schools. Laura described her experiences as follows:

My iPad is now full of science apps I learned from Dr. [ ] class. When I used a solar system journey, which is a free app, to demonstrate my lesson about solar system, the kids were so excited about it.... Yes, the training is absolutely useful for me.

The third question related to informal training. Thirteen other teachers did not have any formal training, so informal training through self-learning or through colleagues' support were common. All 21 participants said that they learned about creative ways of using iPads in the classroom and learned about new apps from their colleagues. Coppi said she knew how to use the iPad with the Elmo document camera just by chance. She came across her colleague's classroom and saw him using it. Vivien mentioned that there were too many apps for her to test and buy. She consulted her school colleagues about what apps they were using before she decided whether or not to buy a specific app. Sharing this concern about apps, David said:

Some of them [apps] are free, but some, we have to pay and we can't return them if we don't like them, so I often checked with my friends before I buy any apps. They are not so expensive, you know, but it's still better to talk with someone who already used them.

From the answers to the three sub-questions, it can be concluded that, except for a group of nine public school teachers who took an iPad-integrated course at the university, the rest of the participants in this study did not have any formal iPad training prior to using it in their classroom. All 21 teachers had to resort to different sources such as self-learning and colleague support to learn more about how to integrate iPads and useful apps into their teaching.

\section{Research question 2: What Factors Affect Teachers Using the iPads in Their Classroom?}

Findings in the previous study indicated that six teachers in a private school used iPads in the classroom on a daily basis, while fifteen teachers in two public schools occasionally used iPads in the classroom. The interview transcripts were divided into two groups, Public School Teachers and Private School Teachers to conduct data analysis and look for common themes between those two data groups.

Two common themes were identified in the Public School Teachers group associated with why they only used iPads occasionally in their classrooms. The first was Lack of Access to an iPad. Campbell said that she did not have an iPad at home so she did not know what applications could be used for specific lessons. Tim mentioned that he had to check out an iPad from the university and then had to return it later. Although he 
loved using the iPad, the over two-hour drive to the university resulted in his not using it as often as he would have liked. Shara explained that though her school bought 30 iPads for the whole school, it was inconvenient to arrange her teaching schedule with the iPads. When she wanted to check out the iPads for her classroom, her colleagues had already reserved them. Jeff explained that although he loved using iPads, he seldom used them in his classroom. The 50 new iPads in his schools used the same Apple account, managed by the school's technology coordinator, which prohibited him from using his personal account to download apps by himself.

Another theme was Existing Technology Availability. Kim said she found iPads useful when taking the iPad-integrated course at the university, but seldom used them in her classroom, "My kids have to do Brainchild [an online learning program for students from grade one to eight] almost every week and taking all of them down to the computer lab to take Brainchild is a lot easier than doing it on the iPad"

Jane said that her classroom had almost all she needed for her teaching such as an Elmo camera, smart board and computer, so she did not see any need to use iPads. She tried using an iPad twice during the last semester and has no plans to use it this semester. Keith shared a similar point of view and showed the leading researcher the technologies he had in his classroom. He agreed that using the iPad was fun, but check out and delivery from the library was time consuming. He found it more convenient to use his laptop and the smart board already available in his classroom.

The transcripts from the six-member Private School Teachers group, presented one common theme, School Leader's Expectation. Eric said he used iPads in the classroom every week. He stated that before the school year started, his school principal introduced the teachers to iPads and asked the librarian to keep a record of iPad use among teachers. The teaching staff in his school understood it was implied that they were expected to use them in their teaching, although the principal did not explicitly require them to do so. $\mathrm{He}$ also said, "Of course, it's kinda fun to try new things, especially the iPad, but probably the main reason we all use it frequently is him [the principal]". Similar to this view, Alice stated that due to her school's expectation that the teachers use new technology in the classroom, every teacher integrated iPads into their teaching in some way on a weekly basis. Anna added, "Using technology in the classroom is our school expectation. You know, we are a small school and [...] you know, he's [the principal] kind of technology oriented."

\section{Discussion and Implications}

\section{Research Discussion}

Responses to three sub-questions showed that besides a group of nine teachers who took a formal iPad-integrated course at the university, the remaining thirteen study participants did not have any formal iPad training before using them in their classroom and were not prepared for iPad integration into their classroom. This finding was in 
line with previous studies in teachers' preparedness and readiness to use technology in their classroom (McCannon \& Crew, 2000; Willis, Austin, \& Willis, 1994). According to a report by the U.S. Congress (1988), only $29 \%$ of the respondents to a national survey of education majors felt prepared to teach with technology. Similarly, a survey by the National Center for Education Statistics (NCES) (2000) found that only one-third of participating teachers responding to the NCES survey reported feeling well prepared or very well prepared to use technology in classroom instruction. According to Jones (2001), providing teachers with access to computers, software, and the Internet was just part of incorporating technology effectively into schools. One of the most decisive factors for successful technology integration into classrooms was teachers' technology training. Studies focusing on lack of teacher preparation or training in the integration of technology into their classrooms have been present for over a decade.

Another area of concern is the type of technology training that should be offered to help teachers integrate new technologies into the classroom. In this study, participating teachers received three separate types of technology training. One group did not have any training. One group attended an iPad training workshop provided by an Apple sales representative. Another group took an iPad integration course at the university. Seven teachers in the same school district indicated

the training workshop provided by an Apple sales representative was not useful. Nine teachers took an iPad-integrated course at the university and found the training was practical, because they were introduced to apps that could be used in their classroom. This finding validates Zhao and Bryant's (2006) research on the effectiveness of intensive curriculum-based technology training. McKenzie (2001) speculated that schools relied too much on unsuccessful business-oriented technology training models for teachers. According to McKenzie, after 20 years of training teachers to use new technologies, a majority of teachers reported feeling ill prepared to use technologies in curriculum-rich ways. Existing training models failed because many software and hardware companies used business examples and knew little or nothing about education. Additionally, corporate-derived training models sometimes put teachers under pressure by rushing them through too many skills in too short a time without sufficient guided practice to reach a comfortable level of familiarity. It was likely the seven teachers who attended a training workshop by an Apple sales representative faced the challenges McKenzie noted. In contrast, providing teachers with professional development opportunities was an effective strategy to help teachers successfully integrate technology into their teaching. Similarly, in this study, nine teachers who took an iPad-integrated course valued what they learned from it about classroom implementation of iPads.

Responses to the first research question also provided an interesting finding: the participating teachers all learned creative ways of using iPads and new apps in their classrooms from their colleagues. This supports McKenzie's findings that teachers working together create an environment of sharing and exchange of experience that helps teachers to learn significantly from one another. Similarly, Alden (2003) proposed that effective programs for training teachers on technology integration should have 
incentives and support, teacher-directed training, adequate access to technology, community partnerships and ongoing informal support as well as training opportunities.

While the teachers at two public schools used iPads one or two times a month to several times over the course of one semester, teachers at a private school used iPads on a weekly basis. It was noteworthy that all participating teachers were considered technology savvy by their school principal, and none of the private school teachers had attended any iPad training. According to the teachers who only sometimes used iPads in the classroom, lack of access to iPads and the ready availability of existing technologies are the two main reasons they did not use iPads as often. In contrast, according to the teachers who used iPads often in classroom, the expectation of school leadership was their driving force. The reasons why teachers in this study did or did not use iPads in the classroom often are in line with factors concerning effective use of technology identified by Hew and Brush (2007). One factor is a lack of access to technology (the public school teachers in this study had to make a reservation to check out iPads and/or could not get access to the Apple store to download and install teaching apps). The second factor is leadership (their private school teaching counterparts used iPads more often because they knew their school administrator's expectation).

\section{Implications}

\section{School districts and/or educational administrators}

This study showed that one of the reasons teachers did not frequently integrate iPads into their teaching was the lack of proper iPad training. This result indicates that the school districts in the study emphasized the purchase and installation of new technology without providing sufficient funding for teachers to learn how to integrate new technology into their teaching. School district administrators should have sufficient financial resources for teacher training or professional development opportunities to help teachers learn how to integrate new technologies into the classroom.

It is also worth mentioning that not all training workshops are effective. As one finding in this study showed, an introductory training workshop by a sales representative did not meet teachers' expectations. One useful way to help teachers successfully integrate iPads into their classrooms was via iPad-integrated courses related to their subject matter, such as the one that many of the participating teachers took at the university. In addition, creating a learning/collaborative community or network within a school district for faculty to share and exchange experiences and ideas in teaching with technology can also help teachers learn from one another. Finally, for teachers, integrating learning technology should be considered a life-long ongoing learning process, not a stand-alone event. School districts should combine and maintain different training modalities, such as both providing a training course and creating a community or network for teachers.

The decision to purchase iPads should also be made carefully and wisely to avoid wasting resources. School district administrators need to address the reasons why the 
school needs to buy iPads especially when classrooms are already equipped with up-todate digital technologies such as Elmos, projectors, computers, and/or a smart board. Another issue with iPad purchasing is how many iPads school districts need to buy. This issue may be related to a question of whether the decision on the number of iPads to use should be based on available financial resources or the needs of the teachers. Findings in this study revealed that the frequency of iPad use was low in the public schools. In this study, those teachers who had only one iPad in the classroom rated the usefulness of iPads very low. In addition, the total real time of iPad use in each teaching period was low.

Another concern regarding the use of iPads in school districts was app installation and management. All of the schools in this study used the same account for all of their iPads. Not all teachers could access the account to download apps from Apple's App Store. This practice discouraged teachers from searching for new apps and implementing them in their teaching. Furthermore, not all apps on the Apple store are free to download, so school districts need to allocate appropriate financial resources for teachers to buy apps. Additionally, each application is often designed for a specific grade level and subject matter. An app for a science class in fifth grade should not be used for a reading class in second grade. School districts should assign someone to be in charge of app installation and management to provide timely technical support to teachers and to avoid app mismanagement on individual iPads.

Finally, the private school teachers used iPads more frequently than their colleagues in public schools. According to those teachers, the reason they used iPads weekly was due to the school leader's expectation. This result implies that school districts ought to consider communicating a clear message to teachers about their expectations. The principal should be more involved in a school district's technology integration initiative, so teachers know what they are expected to do with new technology. In addition, if not all classrooms can be equipped with iPads, the principal should work with the teachers to be sure that each classroom has fair and appropriate access to the technology.

\section{Teachers}

One of the findings in this study showed teachers could make use of iPads flexibly, whether with one iPad or twenty-five iPads. Either configuration could motivate students to learn. This result implies that teachers ought to take into account how frequently they integrate iPads into their teaching. Data from classroom observations also revealed that teachers should take more advantage of prominent iPad features such as interaction and educational apps rather than simply connecting to a projector or via an Elmo and turning the iPad into a traditional laptop or desktop. 


\section{Recommendations}

\section{Data Sources}

Taking into account the limitations encountered in the current study, several recommendations can be made for future research. The data for this study consisted of 21 classroom observations and semi-structured interviews with 21 volunteer teachers at different levels and from different school districts in southern Illinois including both public and private schools. All of the teachers in this study were identified in their school as having a practical understanding of technology. In future studies, a more diverse sample of teachers, who are not identified as technology savvy, would be more beneficial. In addition, future studies may also look at how teachers at each school integrate iPads into their teaching and identify best practices through cross comparison.

Additionally, instead of using semi-structured interviews with each teacher, future studies might consider using focus group interviews. A focus group would likely offer a richer description of the components of such study. Participants in a focus group tend to discuss the questions with each other and respond to one another's answers to the questions. Another advantage of a focus group is that one participant's answer may cause a response from another participant. Another recommendation is to involve students' voices in the study to acquire a deeper understanding of the issue being researched. All in all, studies incorporating a wider range of methods and participants will help to fill in any limitations of the current study and provide a clearer picture of all the factors influencing teacher integration of iPads in the classroom. 


\section{References}

Alden, S. B. (2003). Effective Programs for Training Teachers on the Use of Technology. Technology Teacher Training Programs. Retrieved from http://www. computerlearning.org/articles/Training.htm

Banas, J. R. (2010). Teachers' attitudes toward technology: Considerations for designing

preservice and practicing teacher instruction. Community \& Junior College Libraries, 16(2), 114-127. doi:10.1080/02763911003707552

Becker, H. J. (2001). How are teachers using technology in instruction? Paper presented at the meeting of the American Educational Research Association. Retrieved from http://www.crito.uci.edu/tlc/FINDINGS/special3/How_Are_ Teachers_Using.pdf

Bill \& Melinda Gates Foundation. (2012). Technology and Effective Teaching. Washington, DC. Retrieved from https://edsurge.s3.amazonaws.com/public/ BMGF_Innovation_In_Education.pdf

Bitner, N. \& Bitner, J. (2002). Integrating technology into the classroom: Eight keys to success. Journal of Technology and Teacher Education, 10(1), 95-100.

Center for American Progress (2013). Retrieved from http://www.americanprogress.org/ issues/education/report/2013/06/14/66485/are-schools-getting-a-big-enoughbang-for-their-education-technology-buck/

Christensen, R. (2002). Effects of technology integration education on the attitudes of teachers and students. Journal of Research on Technology in Education, 34(4), 411-433.

Creswell, J. W. (2003). Research design: Qualitative, quantitative, and mixed methods approaches (2nd ed). Thousand Oaks, CA: Sage Publications.

Dupagne, M., \& Krendl, K. A. (1992) Teachers' attitudes toward computers: A review of the literature, Journal of Research on Computing in Education, 24, 420-429.

Hew, K. F., \& Brush, T. (2007). Integrating technology into K-12 teaching and learning: Current knowledge gaps and recommendations for future research. Educational Technology Research and Development, 55, 223-252.

Jones, C. A. (2001). Tech support: Preparing teachers to use technology. Principal Leadership, 1(9), 35-39. 
McCannon, M., \& Crews, T. B. (2000). Assessing the technology training needs of elementary school teachers. Journal of Technology and Teacher Education, 8(2), 111-121.

McClanahan, B., Williams, K., Kennedy, E., \& Tate, S. (2012). A breakthrough for Josh: How use of an iPad facilitated reading improvement. TechTrends, 56(3), 20-28.

McKenzie, J. (2001). How teachers learn technology best. From Now On, 10(6). Retrieved from http://www.fno.org/mar01/howlearn.html.

Merriam, S.B. (1998). Qualitative research and case study applications in education. San Francisco: Jossey -Bass Publishers.

NCES. 2000. Teacher's tools for the 21st century. Washington, D.C.: U.S. Department of Education.

Reynolds, C., \& Morgan, B. A. (2001). Teachers' perceptions of technology in-service: A case study. Society for Information Technology \& Teacher Education, 2001(1), 982-986.

Ringstaff, C., \& Kelley, L. (2002). The learning return on our educational technology investment: A review of findings from research. 1-30. WestEd RTEC.

United State Department of Education. (2005). Toward a new golden age in American education: How the Internet, the law and today's students are revolutionizing expectations. Retrieved from http://www.ed.gov/technology/plan

U.S. Congress, Office of Technology Assessment. (1988). Power on! New tools for teaching and learning. Washington, DC: U.S. Government Printing Office.

Vu, P. (2013). An Inquiry into How iPads are Used in Classrooms (Electronic Thesis or Dissertation). Retrieved from http://opensiuc.lib.siu.edu/cgi/viewcontent. cgi?article $=1708 \&$ context $=$ dissertations

Vu, P., Mclntyre, J., \& Cepero, J. (2014). Teachers' Use of the iPad in Classrooms and Their Attitudes toward Using It. Journal of Global Literacies, Technologies, and Emerging Pedagogies. 2(2), 58-74.

Willis, J., Austin, L., \& Willis, D. (1994). Information technology in teacher education: Surveys of the current status. A report prepared for the Office of Technology Assessment. Houston, TX: University of Houston, College of Education.

Yildirim, S. (2000). Effects of an educational computing course on pre-service and in-service teachers: A discussion and analysis of attitudes and use. Journal of Research on Computing in Education, 32(4), 479-495.

Zhao, Y., \& Bryant, F.-L. (2006). Can teacher technology integration training alone 
lead to high levels of technology integration? A qualitative look at teachers' technology integration after state mandated technology training. Electronic Journal for the Integration of Technology in Education, 5, 53-62.

Zhao, Y., Pugh, K., Sheldon, S., \& Byers, J. (2002). Conditions for classroom technology innovations. Teachers College Record, 104(3), 482-515. 